\title{
Educação ambiental e correntes epistemológicas: análise dos parques nacionais da Região Sudeste do Brasil
}

\section{Amanda Lorena Assis Ferraz ${ }^{1}$, Natália Oliveira Dias ${ }^{2}$, Thallita Mayra Soares Fernandes ${ }^{3}$ e Wanderley Jorge da Silveira Júnior4}

${ }^{1}$ Escola Estadual Deputado Patrus de Sousa. Rua Baronesa de Santa Cecília, 146. Garças. Carandaí-MG, Brasil (CEP 36280-000). Escola Estadual Coronel Alcides Dutra. Rua Manoel Messias de Souza Lima, 101. Centro. Cristiano Otoni-MG, Brasil (CEP 36426-000).

${ }^{2}$ Universidade Federal de São João del-Rei. Programa de Pós-Graduação em Geografia. Campus Tancredo Neves. Avenida Visconde do Rio Preto, S/No, Sala 3.06 RE. São João del-Rei-MG, Brasil (CEP 36301-360). E-mail: nataliaod@yahoo.com.br.

${ }^{3}$ Universidade do Estado do Rio de Janeiro. Programa de Pós-graduação stricto sensu em Letras. Área de Estudos de Teoria da Literatura e Literatura Comparada. Rua São Francisco Xavier, 524, Sala 11.144, Bloco F. Maracanã. Rio de Janeiro-RJ, Brasil (CEP 20559-900).

${ }^{4}$ Universidade Federal de Lavras. Programa de Pós-Graduação em Engenharia Florestal. Caixa Postal 3037. Lavras-MG, Brasil (CEP 37200-000).

Resumo. 0 presente trabalho teve por objetivo analisar quais correntes epistemológicas influenciam as ações, atividades, projetos e programas de educação ambiental nos parques nacionais da Região Sudeste do Brasil. Para tanto, foi realizada uma revisão bibliográfica sobre artigos científicos que abordaram este contexto, bem como foram verificados como os planos de manejo destas unidades norteiam a educação ambiental. Os dados foram analisados após o estudo das 15 correntes político-ideológicas sobre educação ambiental. Concluiu-se que são escassos projetos sobre a temática e que existe uma bipolarização entre as correntes conservadora e crítica, em detrimento das outras 13, perdendo-se assim a oportunidade de desenvolver projetos que atendam as especificidades locais.

Palavras-chave: Educação; Áreas protegidas; Conservação da Natureza.

Abstract. Environmental education and epistemological currents: Analysis of national parks in the Southeast Region of Brazil. This study aimed to analyze what epistemological currents have influence in the environmental education actions,

Recebido $29 / 03 / 2020$

Aceito

28/04/2020

Publicado $30 / 04 / 2020$

Acesso aberto

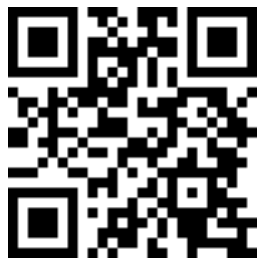


activities, projects, and programs in Brazilian national parks in the Southeast Region. For this purpose a bibliographic review on scientific articles that addressed this context was carried out, and were verified how the management plans of these units guides the environmental education. The data were analyzed after studying the fifteen political-ideological policies currents on environmental education. It was concluded that the projects on the theme are scarce, and that there is a bipolarization between the conservative and critical currents in detriment of the other thirteen, thus leading to the loose of opportunity to develop projects that meet local specificities.

Keywords: Education; Protected areas; Nature conservation.

\author{
(D) 0000-0002-5215-4023 \\ Amanda Lorena Assis \\ Ferraz \\ (1) 0000-0001-7156-4311 \\ Natália Oliveira Dias \\ D) 0000-0001-7279-8814 \\ Thallita Mayra Soares \\ Fernandes \\ D) 0000-0003-0521-8546 \\ Wanderley Jorge da \\ Silveira Júnior
}

\section{Introdução}

As áreas protegidas são territórios definidos e administrados com o objetivo de conservar a biodiversidade, seus traços históricos e culturais. Em sua gênese, eram estas áreas eram criadas a partir da preocupação em proteger locais em processo de degradação. No Brasil, o termo unidade de conservação é utilizado para designar as categorias de áreas protegidas descritas na Lei no 9.985/2000 (Brasil, 2000), que instituiu o Sistema Nacional de Unidades de Conservação da Natureza (SNUC), do qual fazem parte também os parques nacionais (PARNAs), objeto de estudo desta pesquisa. Este tipo de unidade de conservação compõe o grupo de proteção integral, que tem como objetivo a preservação dos ecossistemas naturais de grande relevância ecológica e de beleza cênica, categoria que melhor se enquadra para trabalhos e atividades de educação e interpretação ambiental de acordo com o SNUC (Brasil, 2000).

Segundo o Cadastro Nacional de Unidades de Conservação (MMA, 2019), existem atualmente 74 parques nacionais no Brasil, das quais 12 encontram-se na Região Sudeste do país. Tais parques são administrados pelo Instituto Chico Mendes de Conservação da Biodiversidade (ICMBio). Pelo motivo de sua criação pertencer ao âmbito federal, e apesar de pertencerem a uma mesma região, cada parque possui particularidades que os diferenciam, como as características biológicas, geográficas, econômicas e socioculturais, o que implica na necessidade de intervenções específicas para o desenvolvimento da educação ambiental.

Segundo o art. 1ํㅡ, da Lei oㅗ 9.795/1999, que dispõe sobre a educação ambiental e institui a Política Nacional de Educação Ambiental (Brasil, 1999):

\section{Entendem-se por educação ambiental os processos por meio dos quais o indivíduo e a coletividade constroem valores sociais, conhecimentos, habilidades, atitudes e competências voltadas para a conservação do meio ambiente, bem de uso comum do povo, essencial à sadia qualidade de vida e sua sustentabilidade (Brasil, 1999).}

Niefer (2002) aponta, nesse sentido, que os visitantes de unidade de conservação, por consequência dos Parques, podem vir a auxiliar na conservação da própria unidade quando existem estratégias de manejo adequadas para seus visitantes. Em condescendência a tais pensamentos, temos ainda as correntes epistemológicas da educação ambiental, criadas a fim de facilitar a direção em que a educação deve ser aplicada, uma vez que cada uma delas possui suas características próprias, compartilhar pequenas similaridades ou proximidades na reflexão ou proposta educacional. 
Assim, o presente trabalho teve como objetivo analisar quais correntes epistemológicas influenciam as ações, atividades, projetos e programas de educação ambiental dos parques nacionais brasileiros da região sudeste, com o intuito de compreender como a educação é desenvolvida.

\section{Referencial teórico}

No Brasil, as unidades de conservação são divididas por suas propriedades específicas. Existem dois grupos, de acordo com o art. 7ํㅡ, do SNUC, unidades de proteção integral, que abrange as categorias onde se preservem a natureza e admitam somente o uso indireto dos recursos naturais, e as unidades de uso sustentável, que compatibiliza a conservação da natureza, com o uso sustentável de parcela dos seus recursos naturais (Brasil, 2000).

Os parques nacionais (PARNA) enquadram-se na categoria de proteção integral, definida pelo art. 11, da Lei no 9.985/2000 e têm como objetivo básico:

Preservar ecossistemas naturais de grande relevância ecológica e beleza cênica, possibilitando a realização de pesquisas científicas e o desenvolvimento de atividades de educação e interpretação ambiental, de recreação em contato com a natureza e de turismo ecológico.

Assim, a educação ambiental faz parte do propósito definido pelos PARNAs, o qual compreende o fortalecimento de ações institucionais que promovam a qualificação da participação social na gestão e desenvolvam a sociobiodiversidade (Brasil, 2000).

Tabela 1. Parques Nacionais da Região Sudeste brasileira. Apresenta localização estadual, bioma predominante, data de criação e a existência de plano de manejo.

\begin{tabular}{|l|c|c|c|c|}
\hline Nome da UC & UF & Bioma & $\begin{array}{c}\text { Data de } \\
\text { criação }\end{array}$ & $\begin{array}{c}\text { Plano de } \\
\text { Manejo }\end{array}$ \\
\hline PARNA do Itatiaia & MG, RJ & Mata Atlântica & $14 / 06 / 1937$ & Não \\
\hline PARNA da Serra dos Órgãos & RJ & Mata Atlântica & $30 / 11 / 1939$ & Sim \\
\hline PARNA do Caparó & ES, MG & Mata Atlântica & $24 / 05 / 1961$ & Sim \\
\hline PARNA da Tijuca & RJ & Mata Atlântica & $06 / 07 / 1961$ & Sim \\
\hline PARNA da Serra de Bocaina & RJ, SP & $\begin{array}{c}\text { Mata Atlântica, } \\
\text { Marinho }\end{array}$ & $04 / 02 / 1971$ & Sim \\
\hline PARNA Serra da Canastra & MG & Cerrado & $03 / 04 / 1972$ & Sim \\
\hline PARNA da Serra do Cipó & MG & Cerrado & $25 / 09 / 1984$ & Sim \\
\hline $\begin{array}{l}\text { PARNA Grande Sertão } \\
\text { Veredas Restinga de }\end{array}$ & RG & Cerrado & $12 / 04 / 1989$ & Sim \\
\hline $\begin{array}{l}\text { PARNA Mata Atlântica, } \\
\text { Jurubatiba }\end{array}$ & Marinho & $29 / 04 / 1998$ & Sim \\
\hline PARNA Cavernas do Peruaçu & MG & Caatinga, Cerrado & $21 / 09 / 1999$ & Não \\
\hline PARNA das Sempre Vivas & MG & Cerrado & $13 / 12 / 2002$ & Sim \\
\hline $\begin{array}{l}\text { PARNA da Serra da } \\
\text { Gandarela }\end{array}$ & MG & Mata Atlântica & $13 / 10 / 2014$ & Não \\
\hline
\end{tabular}

Fonte: MMA (2019). 
São 12 parques nacionais que estão localizados na região sudeste (Minas Gerais, Espírito Santo, Rio de Janeiro e São Paulo) e entre eles existem alguns que se localizam em mais de um estado, e portanto, possuem grandes variações de biomas entre si, segundo o Cadastro Nacional de Unidades de Conservação (MMA, 2019).

Tais Parques foram escolhidos por estarem localizados na região central do país, todos abertos à visitação (apenas com a observação para o PARNA das Sempre Vivas que está aberto, mas em processo de estruturação do uso público), e principalmente por incluírem alguns dos PARNAs mais visitados no Brasil, como o da Tijuca, Serra dos Órgãos e Itatiaia (MMA, 2019). A Tabela 1 apresenta os parques nacionais da região sudeste em sua localização, bioma, criação, e a existência de plano de manejo.

A educação ambiental pode ser encontrada no ensino formal e não-formal. $\mathrm{Na}$ primeira circunstância ela é desenvolvida nos currículos escolares em todos os níveis e modalidades de ensino. Já a educação ambiental não-formal incentiva práticas e ações educativas fora do ambiente escolar, buscando a melhoria da qualidade ambiental e inclui a sensibilização da sociedade para a importância das unidades de conservação.

Para Quintas (2004), a educação ambiental deve proporcionar as condições para o desenvolvimento das capacidades necessárias, para que os grupos sociais, em diferentes contextos socioambientais do país, intervenham de modo qualificado tanto na gestão do uso dos recursos ambientais quanto na concepção e aplicação de decisões que afetam a qualidade do ambiente, seja natural ou construído. Ou seja, a educação ambiental atua como instrumento de participação e controle social na gestão ambiental pública.

Dentro dos parques, o objetivo da educação ambiental é mudar a atuação das pessoas em relação à natureza. Deve acarretar, como resultado, a sabedoria e o discernimento nas ações, a fim de assegurar a conservação da biodiversidade e o desenvolvimento socioambiental.

Atualmente, as atividades ecológicas ou ambientais são tratadas como Educação Ambiental, fato que desconsidera o objetivo específico desta, cuja fundamentação consiste em repensar o estilo de vida da humanidade, com o propósito de construir uma consciência crítica das relações sociedade-Natureza dentro de uma visão de mudança global, do modo de vida das sociedades e de sua estrutura (Loureiro, 2002).

Lima (2002) aponta que ao observar-se atentamente o diverso e múltiplo campo da educação ambiental, pode-se perceber que as aparências escondem diferenças sutis e essenciais com relação aos meios e, sobretudo, às finalidades da educação ambiental. Portanto, a definição epistemológica relacionada ao presente estudo refere-se à reflexão diante da natureza, o conhecimento e as relações entre o sujeito e o objeto.

Adjunta a esta reflexão, Layrargues (2004) propõe as correntes conservadora e emancipatória, para auxiliar na identificação dos objetivos da educação ambiental. A primeira está relacionada à conservação da atual estrutura social, com todos as suas características e valores econômicos, políticos, éticos e culturais. A segunda, a emancipatória, é definida pelo compromisso de transformação da ordem social vigente, de renovação plural da sociedade e de sua relação com o meio ambiente.

De acordo com Sauvé (2005), quando se aborda o campo da educação ambiental, preocupando-se com o meio ambiente e a relação com a educação, adota-se de modo subjetivo a forma de conceber e praticar a ação educativa. E partindo desta dificuldade e diversificação de conceitos, surgem a partir das correntes conservadora e emancipatória, as correntes epistemológicas como ferramentas de análise para conduzir e auxiliar as explorações pedagógicas que podem ser trabalhadas, inclusive nos PARNAs, de acordo com a realidade de cada um, assim como as já citadas por Lima (2002).

Ainda segundo Sauvé (2005), são 15 as correntes em educação ambiental, algumas mais antigas que predominaram nas primeiras décadas de educação ambiental (os anos de 1970 e 1980), outras que correspondem a preocupações que surgiram recentemente. Dentro das correntes mais antigas, tem-se a naturalista, a conservacionista/recursista, a 
resolutiva, a sistêmica, a científica, a humanista, a moral/ética. Dentre as mais atuais: a holística, a biorregionalista, a práxica, a crítica, a feminista, a etnográfica, a ecoeducação e a sustentabilidade. Ambas foram desenvolvidas para permitir a flexibilidade nas intervenções pedagógicas de acordo com cada realidade.

A Tabela 2 apresenta resumidamente as diferentes correntes epistemológicas, a concepção dominante do meio ambiente, principal objetivo educativo, enfoque e estratégias dominantes e exemplos de estratégias.

Tabela 2. Correntes da educação ambiental, organizadas conforme a concepção do meio, objetivos, enfoques dominantes e as estratégias utilizadas.

\begin{tabular}{|c|c|c|c|c|}
\hline Correntes & $\begin{array}{l}\text { Concepções } \\
\text { do meio }\end{array}$ & $\begin{array}{c}\text { Objetivos da } \\
\text { educação } \\
\text { ambiental } \\
\end{array}$ & $\begin{array}{c}\text { Enfoques } \\
\text { dominantes }\end{array}$ & $\begin{array}{l}\text { Exemplos de } \\
\text { estratégias }\end{array}$ \\
\hline Naturalista & Natureza & $\begin{array}{l}\text { Reconstruir uma } \\
\text { ligação com a } \\
\text { natureza }\end{array}$ & $\begin{array}{c}\text { Sensorial } \\
\text { Experiencial } \\
\text { Afetivo } \\
\text { Cognitivo } \\
\text { Criativo/Estético } \\
\end{array}$ & $\begin{array}{c}\text { Imersão; } \\
\text { Interpretação; jogos } \\
\text { sensoriais, } \\
\text { atividades de } \\
\text { descoberta. } \\
\end{array}$ \\
\hline $\begin{array}{l}\text { Conservacionista/ } \\
\text { recursista }\end{array}$ & Recurso & $\begin{array}{c}\text { Adotar } \\
\text { comportamentos } \\
\text { de conservação. } \\
\text { Desenvolver } \\
\text { habilidades } \\
\text { relativas à gestão } \\
\text { ambiental } \\
\end{array}$ & $\begin{array}{l}\text { Cognitivo } \\
\text { Pragmático }\end{array}$ & $\begin{array}{l}\text { Guia ou código de } \\
\text { comportamentos; } \\
\text { Projeto de } \\
\text { gestão/conservação. }\end{array}$ \\
\hline Resolutiva & Problema & $\begin{array}{l}\text { Desenvolver } \\
\text { habilidades de } \\
\text { resolução de } \\
\text { problemas (RP): } \\
\text { do diagnóstico à } \\
\text { ação. } \\
\end{array}$ & $\begin{array}{l}\text { Cognitivo } \\
\text { Pragmático }\end{array}$ & $\begin{array}{c}\text { Estudos de casos: } \\
\text { análise de situações } \\
\text { problema; } \\
\text { experiência de RP } \\
\text { associada a um } \\
\text { projeto. }\end{array}$ \\
\hline Sistêmica & Sistema & $\begin{array}{c}\text { Desenvolver o } \\
\text { pensamento } \\
\text { sistêmico: análise } \\
\text { e síntese para uma } \\
\text { visão global. } \\
\text { Compreender as } \\
\text { realidades } \\
\text { ambientais, tendo } \\
\text { em vista decisões } \\
\text { apropriadas. }\end{array}$ & Cognitivo & $\begin{array}{c}\text { Estudo de casos: } \\
\text { análise de sistemas } \\
\text { ambientais. }\end{array}$ \\
\hline Científica & $\begin{array}{l}\text { Objeto de } \\
\text { estudos }\end{array}$ & $\begin{array}{c}\text { Adquirir } \\
\text { conhecimentos em } \\
\text { ciências } \\
\text { ambientais. } \\
\text { Desenvolver } \\
\text { habilidades } \\
\text { relativas à } \\
\text { experiência } \\
\text { científica } \\
\end{array}$ & $\begin{array}{c}\text { Cognitivo } \\
\text { Experimental }\end{array}$ & $\begin{array}{c}\text { Estudo de } \\
\text { fenômenos: } \\
\text { observação } \\
\text { demonstração; } \\
\text { experimentação; } \\
\text { atividade de } \\
\text { pesquisa } \\
\text { hipotético-dedutiva. }\end{array}$ \\
\hline
\end{tabular}


Tabela 2. Continuação.

\begin{tabular}{|c|c|c|c|c|}
\hline Correntes & $\begin{array}{l}\text { Concepções } \\
\text { do meio }\end{array}$ & $\begin{array}{c}\text { Objetivos da } \\
\text { educação ambiental }\end{array}$ & $\begin{array}{c}\text { Enfoques } \\
\text { dominantes }\end{array}$ & $\begin{array}{l}\text { Exemplos de } \\
\text { estratégias }\end{array}$ \\
\hline Humanista & Meio de vida & $\begin{array}{l}\text { Conhecer seu meio de } \\
\text { vida e conhecer-se } \\
\text { melhor em relação a } \\
\text { ele. Desenvolver um } \\
\text { sentimento de } \\
\text { pertença. }\end{array}$ & $\begin{array}{c}\text { Sensorial } \\
\text { Cognitivo } \\
\text { Afetivo } \\
\text { Experimental } \\
\text { Criativo/Estético }\end{array}$ & $\begin{array}{l}\text { Estudo do } \\
\text { meio; } \\
\text { Itinerário } \\
\text { ambiental; } \\
\text { leitura de } \\
\text { paisagem. }\end{array}$ \\
\hline Moral/ética & $\begin{array}{l}\text { Objeto de } \\
\text { valores }\end{array}$ & $\begin{array}{l}\text { Dar prova de } \\
\text { ecocivismo. } \\
\text { Desenvolver um } \\
\text { sistema ético. }\end{array}$ & $\begin{array}{l}\text { Cognitivo } \\
\text { Afetivo } \\
\text { Moral }\end{array}$ & $\begin{array}{l}\text { Análise de } \\
\text { valores; } \\
\text { definição de } \\
\text { valores; crítica } \\
\text { de valores } \\
\text { sociais. } \\
\end{array}$ \\
\hline Holística & $\begin{array}{l}\text { Total } \\
\text { Todo O Ser }\end{array}$ & $\begin{array}{c}\text { Desenvolver as } \\
\text { múltiplas dimensões } \\
\text { de seu ser em } \\
\text { interação com o } \\
\text { conjunto de } \\
\text { dimensões do meio } \\
\text { ambiente. } \\
\text { Desenvolver um } \\
\text { conhecimento } \\
\text { "orgânico" do mundo } \\
\text { e um atuar } \\
\text { participativo em e } \\
\text { com o meio ambiente. }\end{array}$ & $\begin{array}{l}\text { Holístico } \\
\text { Orgânico } \\
\text { Intuitivo } \\
\text { Criativo }\end{array}$ & $\begin{array}{l}\text { Exploração } \\
\text { livre; } \\
\text { visualização, } \\
\text { oficinas de } \\
\text { criação; } \\
\text { integração de } \\
\text { estratégias } \\
\text { complementar } \\
\text { es. }\end{array}$ \\
\hline Biorregionalista & $\begin{array}{l}\text { Lugar de } \\
\text { pertença; } \\
\text { Projeto } \\
\text { comunitário }\end{array}$ & $\begin{array}{c}\text { Desenvolver } \\
\text { competências em } \\
\text { ecodesenvolvimento } \\
\text { comunitário, local ou } \\
\text { regional. }\end{array}$ & $\begin{array}{l}\text { Cognitivo } \\
\text { Afetivo } \\
\text { Experiencial } \\
\text { Pragmático } \\
\text { Criativo }\end{array}$ & $\begin{array}{l}\text { Exploração do } \\
\text { meio } \\
\text { Projeto } \\
\text { comunitário } \\
\text { Criação de } \\
\text { ecoempresas } \\
\end{array}$ \\
\hline Práxica & $\begin{array}{c}\text { Ação/reflexã } \\
\text { o }\end{array}$ & $\begin{array}{l}\text { Aprender em, para e } \\
\text { pela ação. } \\
\text { Desenvolver } \\
\text { competências de } \\
\text { reflexão. } \\
\end{array}$ & Práxico & Pesquisa-ação \\
\hline Crítica & $\begin{array}{c}\text { Objeto de } \\
\text { transformaç } \\
\text { ão, } \\
\text { Lugar de } \\
\text { emancipação }\end{array}$ & $\begin{array}{c}\text { Desconstruir as } \\
\text { realidades } \\
\text { sócioambientais } \\
\text { visando a transformar } \\
\text { o que causa } \\
\text { problemas. }\end{array}$ & $\begin{array}{c}\text { Práxico } \\
\text { Reflexivo } \\
\text { Dialogístico }\end{array}$ & $\begin{array}{c}\text { Análise de } \\
\text { discurso; } \\
\text { estudo de caso; } \\
\text { debates; } \\
\text { pesquisa-ação }\end{array}$ \\
\hline Feminista & $\begin{array}{l}\text { Objeto de } \\
\text { solicitude }\end{array}$ & $\begin{array}{l}\text { Integrar os valores } \\
\text { feministas à relação } \\
\text { com o meio ambiente. }\end{array}$ & $\begin{array}{c}\text { Intuitivo } \\
\text { Afetivo } \\
\text { Simbólico } \\
\text { Espiritual } \\
\text { Criativo/Estético }\end{array}$ & $\begin{array}{c}\text { Estudos de } \\
\text { casos; imersão; } \\
\text { oficinas de } \\
\text { criação; } \\
\text { atividade de } \\
\text { intercâmbio, de } \\
\text { comunicação. }\end{array}$ \\
\hline
\end{tabular}


Tabela 2. Continuação.

\begin{tabular}{|c|c|c|c|c|}
\hline Correntes & $\begin{array}{c}\text { Concepções do } \\
\text { meio }\end{array}$ & $\begin{array}{l}\text { Objetivos da } \\
\text { educação } \\
\text { ambiental } \\
\end{array}$ & $\begin{array}{c}\text { Enfoques } \\
\text { dominantes }\end{array}$ & $\begin{array}{l}\text { Exemplos de } \\
\text { estratégias }\end{array}$ \\
\hline Etnográfica & $\begin{array}{c}\text { Território Lugar } \\
\text { de identidade } \\
\text { Natureza/ } \\
\text { Cultura }\end{array}$ & $\begin{array}{c}\text { Reconhecer a } \\
\text { estreita ligação } \\
\text { entre natureza e } \\
\text { cultura. Aclarar sua } \\
\text { própria cosmologia. } \\
\text { Valorizar a } \\
\text { dimensão cultural } \\
\text { de sua relação com } \\
\text { o meio ambiente. }\end{array}$ & $\begin{array}{c}\text { Experiencial } \\
\text { Intuitivo } \\
\text { Afetivo } \\
\text { Simbólico } \\
\text { Espiritual } \\
\text { Criativo/Estético }\end{array}$ & $\begin{array}{c}\text { Contos, } \\
\text { narrações e } \\
\text { lendas; } \\
\text { estudos de } \\
\text { caso; imersão; } \\
\text { camaradagem. }\end{array}$ \\
\hline Ecoeducação & $\begin{array}{c}\text { Pólo de interação } \\
\text { para a formação } \\
\text { pessoal }\end{array}$ & $\begin{array}{c}\text { Experimentar o } \\
\text { meio ambiente para } \\
\text { experimentar-se e } \\
\text { formar-se em e pelo } \\
\text { meio ambiente. } \\
\text { Construir sua } \\
\text { relação com o } \\
\text { mundo, com outros } \\
\text { seres que não sejam } \\
\text { humanos. } \\
\end{array}$ & $\begin{array}{c}\text { Experiencial } \\
\text { Sensorial } \\
\text { Intuitivo } \\
\text { Afetivo } \\
\text { Simbólico } \\
\text { Criativo }\end{array}$ & $\begin{array}{l}\text { Relato de vida; } \\
\text { imersão; } \\
\text { exploração } \\
\text { Introspecção; } \\
\text { escuta } \\
\text { sensível; } \\
\text { alternância } \\
\text { subjetiva/obje } \\
\text { tiva; } \\
\text { brincadeiras } \\
\end{array}$ \\
\hline $\begin{array}{l}\text { Sustentação e da } \\
\text { sustentabilidade }\end{array}$ & $\begin{array}{l}\text { Recursos para o } \\
\text { desenvolvimento } \\
\text { econômico e } \\
\text { compartilhados }\end{array}$ & $\begin{array}{c}\text { Promover um } \\
\text { desenvolvimento } \\
\text { econômico } \\
\text { respeitoso dos } \\
\text { aspectos sociais e } \\
\text { do meio ambiente. } \\
\text { Contribuir para esse } \\
\text { desenvolvimento. }\end{array}$ & $\begin{array}{l}\text { Pragmático } \\
\text { Cognitivo }\end{array}$ & $\begin{array}{l}\text { Estudo de } \\
\text { casos; } \\
\text { Experiência de } \\
\text { resolução de } \\
\text { problemas; } \\
\text { projeto de } \\
\text { desenvolvime } \\
\text { nto de } \\
\text { sustentação e } \\
\text { sustentável. }\end{array}$ \\
\hline
\end{tabular}

Fonte: Adaptado de Sauvé (2005).

\section{Materiais e métodos}

Neste estudo, a coleta e análise dos dados foram realizadas por meio de metodologias qualitativas, das quais se utilizou revisão bibliográfica de artigos científicos a partir de 1999 (ano da criação da Política Nacional de Educação Ambiental no Brasil), que abrangem e discutem educação ambiental em parques nacionais e documentos oficiais destas Unidades e que possibilitou identificar as correntes epistemológicas adotadas nesta tipologia de unidades de conservação. Para tanto, a pesquisa foi dividida em três etapas.

Na primeira, foi realizada revisão bibliográfica em livros e artigos científicos sobre as 15 correntes epistemológicas apontadas por Sauvé (2005).

Na segunda, foram investigados nas plataformas científicas Google Scholar, Scielo e Periódicos CAPES artigos publicados a partir de 1999 que versem sobre programas, projetos, ações e atividades de educação ambiental realizadas pelos parques nacionais. Para tal fim, utilizou-se os seguintes grupos de palavras-chave: Educação Ambiental, Parque Nacional e Brasil. Com o intuito de ampliar a abrangência dos resultados, as palavras-chave foram traduzidas para o inglês e também pesquisadas, Enviromental 
education; National Park; Brazil. Documentos identificados nos sites oficiais das unidades que continham informações sobre a educação ambiental, também foram utilizados.

A terceira e última etapa compreendeu a verificação dos dados extraídos após as pesquisas e a assimilação dos projetos e atividades de educação ambiental realizados nos parques nacionais da região sudeste do Brasil, consideradas sob a leitura das correntes propostas por Sauvé (2005). Ao final da análise, foi possível identificar quais delas mais norteiam a educação ambiental nestes parques nacionais, e se elas fazem parte da polarização conservadora ou emancipatória. Posteriormente, foram discutidos os pontos positivos e negativos do desenvolvimento da educação ambiental.

\section{Resultados}

Os resultados foram separados em duas partes de acordo com as fontes de pesquisa bibliográfica. A primeira parte apresenta as informações coletadas em artigos científicos, revistas, periódicos e sites oficiais. A segunda, reúne as informações provenientes dos planos de manejo dos PARNAs junto às informações dos sites do ICMBio.

Essa separação foi feita a fim de facilitar o entendimento dos resultados e viabilizar uma possível comparação de informações que podem ser significativas para estudos posteriores. Com a pesquisa bibliográfica em artigos, foi criado um espaço amostral de 21 textos científicos para a identificação das correntes em educação ambiental, que são apresentados resumidamente na Tabela 3, na qual constam quantos trabalhos foram encontrados sobre cada parque, seus respectivos autores e a identificação das correntes de cada um deles. Ainda na tabela, estão os dados coletados sobre os sites oficiais a respeito da educação ambiental.

Tabela 3. Resumo dos dados obtidos na primeira etapa da pesquisa bibliográfica realizada em artigos e sites oficiais.

\begin{tabular}{|c|c|c|c|c|}
\hline PARNA & Artigo & Corrente & Site oficial & $\begin{array}{c}\text { Informações } \\
\text { sobre a } \\
\text { educação } \\
\text { ambiental } \\
\text { realizada } \\
\end{array}$ \\
\hline Caparaó & $\begin{array}{l}\text { Torres e Cosenza } \\
\text { (2017) } \\
\text { Padoan (2015) } \\
\text { Ribeiro (2008) }\end{array}$ & $\begin{array}{l}\text { 1. Relata não existir } \\
\text { educação ambiental no } \\
\text { parque } \\
\text { 2. Conservacionista } \\
\text { 3. Crítica }\end{array}$ & Não possui & Não possui \\
\hline $\begin{array}{l}\text { Cavidade do } \\
\text { Peruaçu }\end{array}$ & $\begin{array}{l}\text { Não possui artigos } \\
\text { relacionados ao tema }\end{array}$ & - & Não possui & Não possui \\
\hline Gandarela & $\begin{array}{l}\text { Não possui artigos } \\
\text { relacionados ao tema }\end{array}$ & - & Não possui & Não possui \\
\hline Itatiaia & $\begin{array}{l}\text { Almeida e Costa } \\
\text { (2017) } \\
\text { Oliveira et al., (2015) } \\
\text { Barros (2003) } \\
\text { Ávila (2001) }\end{array}$ & $\begin{array}{l}\text { 1. Naturalista } \\
\text { 2. Conservacionista } \\
\text { 3. Critica } \\
\text { 4. Conservacionista }\end{array}$ & Não possui & Não possui \\
\hline $\begin{array}{l}\text { Restinga de } \\
\text { Jurubatiba }\end{array}$ & $\begin{array}{l}\text { Botelho (2018) } \\
\text { Costa et al. (2015) } \\
\text { Farjalla et al. (2011) } \\
\text { Fuentes et al. (2011) } \\
\text { Vainer (2010) }\end{array}$ & $\begin{array}{l}\text { 1. Crítica } \\
\text { 2. Crítica } \\
\text { 3. Conservacionista } \\
\text { 4. Crítica } \\
\text { 5. Conservacionista }\end{array}$ & Possui & Não possui \\
\hline
\end{tabular}


Tabela 3. Continuação.

\begin{tabular}{|c|c|c|c|c|}
\hline PARNA & Artigo & Corrente & Site oficial & $\begin{array}{c}\text { Informações } \\
\text { sobre a } \\
\text { educação } \\
\text { ambiental } \\
\text { realizada } \\
\end{array}$ \\
\hline $\begin{array}{l}\text { Sempre } \\
\text { Vivas }\end{array}$ & $\begin{array}{l}\text { Não possui artigos } \\
\text { relacionados ao tema }\end{array}$ & - & Não possui & Não possui \\
\hline $\begin{array}{ll}\text { Serra } & \mathrm{da} \\
\text { Canastra } & \end{array}$ & Rocha et al. (2018) & 1. Conservacionista & Possui & Não possui \\
\hline $\begin{array}{ll}\text { Serra } & \text { de } \\
\text { Bocaina } & \end{array}$ & Conti et al. (2011) & 1. Crítica & Não possui & Não possui \\
\hline $\begin{array}{l}\text { Serra do } \\
\text { Cipó }\end{array}$ & $\begin{array}{l}\text { Campos e Filetto (2011) } \\
\text { Campos et al. (2011) } \\
\text { Sato (2007) }\end{array}$ & $\begin{array}{l}\text { 1. Relata não existir } \\
\text { educação ambiental no } \\
\text { parque } \\
\text { 2. Crítica } \\
\text { 3. Naturalista/Crítica }\end{array}$ & Não possui & Não possui \\
\hline $\begin{array}{ll}\text { Serra dos } \\
\text { Órgãos }\end{array}$ & Santos et al. (2007) & 1. Crítica & Possui & Não possui \\
\hline $\begin{array}{l}\text { Sertão } \\
\text { Veredas }\end{array}$ & $\begin{array}{l}\text { Não possui artigos } \\
\text { relacionados ao tema }\end{array}$ & - & Não possui & Não possui \\
\hline Tijuca & $\begin{array}{l}\text { Rocha et al. (2017) } \\
\text { Góes et al. (2016) } \\
\text { Almeida et al. (2013) }\end{array}$ & $\begin{array}{l}\text { 1. Holística } \\
\text { 2. Práxica/Holística } \\
\text { 3. Conservacionista }\end{array}$ & Possui & Não possui \\
\hline
\end{tabular}

Já com a pesquisa sobre planos de manejo, foi verificada a existência de projetos e atividades de educação ambiental em alguns parques, os quais são mostrados resumidamente na Tabela 4, na qual se especifica em quais parques existem e quais são desenvolvidos. A tabela também exibe as informações adquiridas por meio do site ICMBio, no qual apenas o PARNA do Caparaó evidenciou os quatro projetos, sendo eles o Projeto Doces Matas, Projeto Comunidade Aprendizagem, Consórcio Capixaba dos Municípios Vizinhos ao Parque e outras atividades dos municípios do entorno. Contudo, é importante ressaltar a dificuldade em encontrar dados sobre os projetos realizados pelos parques quando a educação ambiental está envolvida.

Tabela 4. Resumo dos dados obtidos na segunda etapa da pesquisa bibliográfica referente aos Planos de Manejo e site do ICMBio.

\begin{tabular}{|c|c|c|c|}
\hline PARNA & $\begin{array}{c}\text { Informações nas Fichas } \\
\text { Técnicas dos Planos de } \\
\text { Manejo } \\
\end{array}$ & Site ICMBio & $\begin{array}{c}\text { Correntes } \\
\text { identificadas }\end{array}$ \\
\hline Caparaó & $\begin{array}{c}\text { Realiza atividades pontuais, } \\
\text { principalmente em escolas } \\
\text { locais }\end{array}$ & $\begin{array}{c}4 \text { projetos de } \\
\text { educação ambiental }\end{array}$ & Conservacionista \\
\hline $\begin{array}{l}\text { Caverna do } \\
\text { Peruaçu }\end{array}$ & $\begin{array}{c}\text { Não possuem educação } \\
\text { ambiental }\end{array}$ & $\begin{array}{c}\text { Não possui projetos } \\
\text { de educação } \\
\text { ambiental }\end{array}$ & Não possui \\
\hline Gandarela & Não possui Plano de Manejo & $\begin{array}{c}\text { Não possui projetos } \\
\text { de educação } \\
\text { ambiental } \\
\end{array}$ & Não possui \\
\hline
\end{tabular}


Tabela 4. Continuação.

\begin{tabular}{|c|c|c|c|}
\hline PARNA & $\begin{array}{c}\text { Informações nas Fichas } \\
\text { Técnicas dos Planos de } \\
\text { Manejo }\end{array}$ & Site ICMBio & $\begin{array}{c}\text { Correntes } \\
\text { identificadas }\end{array}$ \\
\hline Itatiaia & $\begin{array}{c}\text { Principal projeto é o Programa } \\
\text { de Visitas Orientadas, existem } \\
\text { mais projetos em parceria com } \\
\text { o MMA }\end{array}$ & $\begin{array}{l}\text { Possui a informação } \\
\text { do Plano de Manejo }\end{array}$ & Crítica \\
\hline $\begin{array}{l}\text { Restinga de } \\
\text { Jurubatiba }\end{array}$ & $\begin{array}{l}\text { Insuficiente, uma das poucas } \\
\text { atividades realizadas é o } \\
\text { Projeto Ecolagoas em salas de } \\
\text { aula }\end{array}$ & $\begin{array}{l}\text { Possui a informação } \\
\text { do Plano de Manejo }\end{array}$ & Conservacionista \\
\hline Sempre Vivas & $\begin{array}{c}\text { Não possuem educação } \\
\text { ambiental }\end{array}$ & $\begin{array}{l}\text { Possui a informação } \\
\text { do Plano de Manejo }\end{array}$ & Não possui \\
\hline Serra da Canastra & Possui, mas sem programação & $\begin{array}{l}\text { Possui a informação } \\
\text { do Plano de Manejo }\end{array}$ & Não possui \\
\hline Serra de Bocaina & Incipiente & $\begin{array}{l}\text { Possui a informação } \\
\text { do Plano de Manejo }\end{array}$ & Não possui \\
\hline Serra do Cipó & Existe, de forma assistemática & $\begin{array}{l}\text { Possui a informação } \\
\text { do Plano de Manejo }\end{array}$ & Não possui \\
\hline Serra dos Órgãos & $\begin{array}{l}\text { Projeto Cenário Verde voltados } \\
\text { para as escolas locais e Projeto } \\
\text { Boa Vizinhança desenvolvendo } \\
\text { relação do parque com a } \\
\text { comunidade }\end{array}$ & $\begin{array}{l}\text { Possui encontros de } \\
\text { educação ambiental }\end{array}$ & Conservacionista \\
\hline Sertão Veredas & $\begin{array}{l}\text { educação ambiental em } \\
\text { andamento, abrange as escolas, } \\
\text { moradores e agricultores locais }\end{array}$ & $\begin{array}{l}\text { Possui a informação } \\
\text { do Plano de Manejo }\end{array}$ & Conservacionista \\
\hline Tijuca & $\begin{array}{l}\text { Projetos de integração com } \\
\text { escolas e comunidades do } \\
\text { entorno; cursos de educação } \\
\text { ambiental para servidores e } \\
\text { agentes multiplicadores; } \\
\text { palestras, seminários e ventos } \\
\text { dirigidos aos usuários e } \\
\text { visitantes }\end{array}$ & $\begin{array}{l}\text { Possui a informação } \\
\text { do Plano de Manejo }\end{array}$ & Crítica \\
\hline
\end{tabular}

\section{Discussão}

A pesquisa bibliográfica apontou 21 artigos, dos quais 19 puderam ter suas correntes identificadas. Os estudos correspondem ao período de 2001 a 2018, ou seja, 17 anos. A relação dos artigos em escala temporal mostra certa deficiência de atividades e ações de educação ambiental e de pesquisas realizadas sobre educação ambiental nos Parques, já que a educação ambiental é uma atividade prevista nos objetivos desta categoria de UC (Brasil, 2000) e é de fundamental importância para a conservação da 
biodiversidade. Conforme apontado por Rodrigues e Nascimento (2016), é uma ferramenta para estabelecer um novo conhecimento, um novo pensamento, capaz enfrentar os desafios socioambientais provenientes do saber e da ciência empregados pelo paradigma dominante.

Este resultado demonstra que poucas correntes são utilizadas, pois são 15 as listadas por Sauvé (2005). Neste sentido, esperava- se certa heterogeneidade, caso os Parques adotassem as concepções associadas às suas características e peculiaridades. Contudo elas se encaixam na polarização discutida por Lima (2002), dado que apontam as correntes Conservadora e Crítica como as norteadoras das ações e projetos de educação ambiental nos Parques.

Os resultados das identificações das correntes demonstraram que 36,8\% (7) artigos foram definidos como conservacionistas, e a corrente crítica foi identificada em dos $42,1 \%$ (8) dos artigos. Na primeira, o objetivo principal é desenvolver habilidades relativas à gestão ambiental e na segunda, é desconstruir as realidades socioambientais sob a intenção de transformar o que causa problemas, bem como visa a sensibilizar as pessoas sobre as áreas protegidas (Sauvé, 2005).

Esses resultados demonstraram que a polarização deve-se ao fato das correntes conservacionista e crítica estarem alinhadas respectivamente às macrotendências, conservadora e emancipatória, ambas pontuadas por Lima (2002).Todavia, os parques, ao investirem em ações, projetos e atividades norteados pelas concepções conservadora de educação ambiental, excluem as pessoas do processo de conservação, pois a baixa participação e representação social marcam esta corrente epistemológica (Lima, 2002).

Ao contrário, a educação ambiental crítica/emancipatória promoveria ações de autonomia e transformação sobre aspectos negativos existentes, como aponta Loureiro (2002), uma vez que seu propósito é estabelecer uma consciência crítica sobre as relações entre Sociedade-Natureza e promover mudanças de acordo com a realidade de vida e organização social.

A corrente naturalista que atua em reconstruir um vínculo com a natureza a partir de experiências sensoriais e cognitivas (sauvé, 2005), teve um reconhecimento de 5,3\% (1) dos artigos. Com a mesma porcentagem ficou a corrente holística (1 artigo), que segundo Sauvé (2005), opera em várias extensões do ser relacionadas às diversas extensões do meio ambiente através de uma exploração livre e criativa e mecanismos complementares. No restante dos artigos houve a identificação de mais de uma corrente nos trabalhos e projetos de educação ambiental nesses Parques, divididos em Naturalista/Crítica com 5,3\% (1) e Práxica/Holística também com 5,3\% (1), totalizando $10,5 \%$ (2) dos artigos. É necessário recordar que a corrente práxica atua com ação/reflexão, ou seja, aprende com as ações e reflexões de suas práticas, para garantir resolutividade (Sauvé, 2005).

Os resultados da avaliação dos planos de manejo e sites oficiais apontaram falta de atualização ou até mesmo falta de planejamento da educação ambiental, pois dos 12 pesquisados 66,6\% (8) evidenciaram a existência da educação ambiental em seus planos de manejo, mas apenas metade (6) relatou quais são os projetos atuantes. Também nos planos de manejo, foi observada a polarização já identificada nas pesquisas publicadas. Neste caso, se destaca a corrente conservacionista, pois 33,3\% (4) dos Parques adotam projetos Conservacionistas enquanto 16,6\% (2) possuem projetos pautados pela educação ambiental Crítica/emancipatória. Em sites do ICMBio, as informações sobre projetos em Educação ambiental foram escassas, pois se declara a presença apenas nos PARNAs do Caparaó, com quatro projetos, e Serra dos Órgãos, com um projeto. Todos eles baseados em concepções Conservacionistas.

Em suma, é perceptível a insuficiência de programas e projetos de educação ambiental, o que afeta diretamente a conservação dos Parques. A polarização entre as correntes conservadora e crítica priva as unidades das oportunidades técnicas e 
metodológicas das ouras 13 concepções identificadas por Sauvé (2005). Assim, os parques que desenvolvem a educação ambiental privam-se da possibilidade de ampliar as oportunidades de sensibilizar e incluir as pessoas nos processos que marcam a conservação in situ, pois prevalece o uso de técnicas e metodologias conservadoras que não anseiam a transformação da realidade vigente, ao contrário, reforçam a dicotomia entre sociedade e natureza. E assim, ameaçam os próprios objetivos conservacionistas.

\section{Conclusões}

Ao analisar as ações, atividades, projetos e programas de educação realizados nos parques nacionais da região sudeste do Brasil, verificou-se que a ausência de ações e projetos nas unidades é uma realidade, e onde ocorrem, são incipientes. Existe uma polarização entre as correntes conservacionista e crítica. Todavia, a primeira possui uma presença hegemônica, enquanto as naturalista, práxica e holística, ocorrem de forma muito reduzida.

Este estudo aponta para a urgente necessidade de mais ações, projetos e atividades de educação ambiental nos parques. Entretanto, para que o processo de conservação aconteça de forma efetiva, é fundamental que esta ampliação aconteça a partir do entendimento de todos os envolvidos sobre as amplas e férteis possibilidades de educação ambiental disponíveis há décadas. Neste sentido, é prudente que o poder público, responsável pela gestão dos Parques Nacionais, seja o fomentador ou o responsável por esta capacitação.

\section{Conflito de interesses}

Os autores declaram não haver conflito de interesses.

\section{Referências}

Almeida, A. C. F.; Costa, N. M. C. Do material ao imaginário: uma análise interpretativa das percepções ambientais dos condutores do Parque Nacional do Itatiaia (RJ). Revista

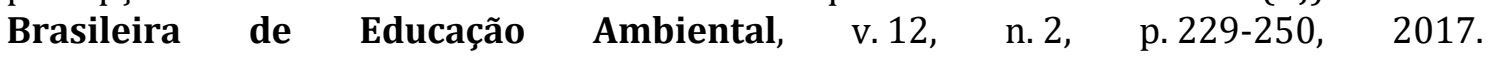
https://doi.org/10.34024/revbea.2017.v12.2408

Almeida, E. S.; Zaú, A. S.; Machado, A. S.; Oliveira, G. M. A.; Costa, V. G. Bioindicadores de impactos em trilhas em uma unidade de conservação de proteção integral (PARNA Tijuca), no domínio da Mata Atlântica. Anais do II Congresso Nacionais de Planejamento e Manejo de Trilhas e I Colóquio Brasileiro da Red Latino Americana de Denderismo, Rio de Janeiro, 2013.

Ávila, M. C. A. D. Eficácia da política ambiental em seus aspectos sociais e jurídicos, tomando por base o Parque Nacional do Itatiaia. Revista Justitia, v. 63, n. 194, p. 95-109, 2001.

Barros, M. I. A. Caracterização da visitação, dos visitantes e avaliação dos impactos ecológicos e recreativos do planalto do Parque Nacional do Itatiaia. São Pauo: USP, 2003. (Dissertação de mestrado).

Botelho, E. S. Visitação e turismo em parques nacionais: o caso do Parque Nacional da Restinga de Jurubatiba (RJ). Rio de Janeiro: UFRJ, 2018. (Tese de doutorado). 
Brasil. Lei no 9.985, de 18 de julho de 2000. Regulamenta o art. 225, § 1ํ, incisos I, II, III e VII da Constituição Federal, institui o Sistema Nacional de Unidades de Conservação da Natureza e dá outras providências. Disponível em: <http://www.planalto.gov.br/ ccivil_03/leis/19985.htm>. Acesso em: 19 out. 2019.

Brasil. Lei no 9.795, 27 de abril de 1999. Dispõe sobre a educação ambiental, institui a Política Nacional de Educação Ambiental e dá outras providências. Disponível em: <http://www.planalto.gov.br/ccivil_03/LEIS/L9795.htm>. Acesso em: 30/11/2019.

Campos, R. F.; Filetto, F. Análise do perfil, da percepção ambiental e da qualidade da experiência dos visitantes da Serra do Cipó (MG). Revista Brasileira de Ecoturismo, v. 4, n. 1, p. 69-94, 2011. https://doi.org/10.34024/rbecotur.2011.v4.5902

Campos, R. F.; Vasconcelos, F. C. W.; Félix, L. A. G. A Importância da caracterização dos visitantes nas ações de ecoturismo e educação ambiental do Parque Nacional da Serra do Cipó/MG. Revista Turismo em Análise, v. 22, n. 2, p.397-427, 2011. https://doi.org/10.11606/issn.1984-4867.v22i2p397-427

Conti, B. R.; Irving, M. A.; Corrêa, F. V. Ecoturismo e proteção da natureza no Parque Nacional da Serra da Bocaina: o caso da Vila de Trindade (Paraty, RJ). Revista Brasileira de Ecoturismo, v. 4, n. 4, p. 503, 2011. https://doi.org/10.34024/rbecotur.2011.v4.5937

Costa, R. N.; Yu-Ming, J.; Sánchez, C. O encontro do cinema com a educação ambiental crítica no Parque Nacional da Restinga de Jurubatiba. Anais do VIII Encontro Pesquisa em Educação Ambiental, 2015.

Farjalla, M. S.; Bozelli, R. L.; Loureiro, C. F. B. Justiça ambiental e reconhecimento: o caso do Parque Nacional da Restinga de Jurubatiba. Revista Floresta e Ambiente, v. 18, n. 4, p. 460-468, 2011. https://doi.org/10.4322/floram.2011.065

Fuentes, N. M. M.; Costa, R. N.; Abreu, T. B.; Ruta, C. Construção de oficinas pedagógicas com a utilização de ferramentas audiovisuais com os moradores do entorno do Parque Nacional da Restinga de Jurubatiba. Anais do VIII Encontro Nacional de Pesquisa em Educação em Ciências, 2011.

Góes, Y. C. B.; Pin, J. R. O.; Rodrigues, M. B. R. Análise de percepção ambiental de estudantes durante visitas guiadas no Parque Nacional da Tijuca. Anais do V Simpósio de Gestão Ambiental e Biodiversidade, 2016.

Layrargues, P. P. (Coord.). Identidades da educação ambiental brasileira. Brasília: Ministério do Meio Ambiente, 2004.

Lima, G. F. C. Crise ambiental, educação e cidadania: os desafios da sustentabilidade emancipatória. In: Layrargues, P. P.; Castro, R. S.; Loureiro, C. F. B. (Orgs.). Educação ambiental: repensando o espaço da cidadania. São Paulo: Cortez, 2002. p. 11-12.

Loureiro, C. F. B. Educação ambiental crítica: princípios teóricos e metodológicos. Rio de Janeiro: Hotbook, 2002.

MMA - Ministério do Meio Ambiente. Cadastro Nacional de Unidades de Conservação CNUC. 2019. Disponível em: <https://www.mma.gov.br/images/arquivos/ A0_Brasil_600_DPI_02_2019.pdf>. Acesso em: 25 nov. 2019.

Niefer, I. A. Análise do perfil dos visitantes das Ilhas de Superagui e do Mel: marketing como instrumento para um turismo sustentável. Curitiba: UFPR, 2002. (Tese de doutorado). 
Oliveira, M. P.; Ferreira, E.; Ribeiro, M.; Souza, J.; Richter, M. Perfil, percepção e opinião dos visitantes do Parque Nacional do Itatiaia (RJ) em períodos de maior demanda. Anais do Uso Público em Unidades de Conservação, v. 3, n. 6, p. 86-96, 2015.

Padoan, L. L. F. Turismo em unidade de conservação: um exercício de imersão no Parque Nacional do Caparaó, MG/ES. Anais do Uso Público em Unidades de Conservação, v. 3, n. 6, p. 37-51, 2015.

Quintas, J. S. Educação no processo de gestão ambiental pública: a construção do ato pedagógico. In: Layrargues, P. P. (Coord.). Identidades da educação ambiental brasileira. Brasília: Ministério do Meio Ambiente, 2004. p.113-140.

Ribeiro, F. N. Tessituras da educação ambiental na Região do Caparaó Capixaba: a formação dos sujeitos engajados. Florianópolis: UFSC, 2008. (Dissertação de mestrado).

Rocha, I. L. O.; Carvalho, R. C. R.; Rocha, W. W.; Reis, M. J.; Pires, B. S. Avaliação da aplicação de carga antrópica em uma trilha no Parque Nacional da Serra da Canastra (Estado de Minas Gerais, Brasil). Revista Brasileira de Gestão Ambiental e Sustentabilidade, v. 5, n. 9, p. 291-300, 2018. https://doi.org/10.21438/rbgas.050920

Rocha, M. 0 potencial das trilhas ecológicas como instrumento de sensibilização ambiental: o caso do Parque Nacional da Tijuca. Revista e-Mosaicos, v. 6, n. 12, p. 81-96, 2017. https://doi.org/10.12957/e-mosaicos.2017.27916

Rodrigues, J. C. R.; Nascimento, R. S. Saber ambiental, complexidade e educação ambiental. Revista Brasileira de Educação Ambiental, v. 11, n. 5, p. 152-165, 2016. https://doi.org/10.34024/revbea.2016.v11.2363

Santos, F.; Freire, I.; Brasileiro, R.; Mussi, S. Conselho consultivo do Parque Nacional da Serra dos Órgãos: um espaço efetivo de educação ambiental. Rio de Janeiro: ICMBio, 2007.

Sato, C. S. Parque Nacional Serra do Cipó, MG: percepção ambiental e estabelecimento de áreas para educação. São Paulo: USP, 2007. (Tese de doutorado).

Sauvé, L. Uma das cartografias em correntes em educação ambiental. In: Sato, M.; Carvalho, I. C. M. Educação ambiental: pesquisa e desafios. Porto Alegre: Artmed, 2005. p. 17-42.

Torres, R.; Cosenza, B. Avaliação da gestão e sustentabilidade do Parque Nacional do Caparaó (Estados de Minas Gerais e Espírito Santo, Brasil. Revista Brasileira de Gestão Ambiental e Sustentabilidade, v. 4, n. 8, p. 395-417, 2017. https://doi.org/10.21438/ rbgas. 040813

Vainer, A. G. Conflitos ambientais em evidência na criação e manejo de um parque nacional: o caso do Parque Nacional da Restinga de Jurubatiba. Anais do XIX Encontro Nacional do CONPEDI, 2010.

Informação da Licença: Este é um artigo Open Access distribuído sob os termos da Licença Creative Commons Attribution, que permite uso irrestrito, distribuição e reprodução em qualquer meio, desde que a obra original seja devidamente citada. 